\title{
A Novel Ratiometric Probe Based on Nitrogen-Doped Carbon Dots and Rhodamine B Isothiocyanate for Detection of $\mathrm{Fe}^{3+}$ in Aqueous Solution
}

\author{
Lin Liu, Lu Chen, Jiangong Liang, Lingzhi Liu, and Heyou Han \\ State Key Laboratory of Agricultural Microbiology, College of Science, Huazhong Agricultural University, Wuhan 430070, China \\ Correspondence should be addressed to Lu Chen; chenlu@mail.hzau.edu.cn and Jiangong Liang; liangjg@mail.hzau.edu.cn
}

Received 30 November 2015; Accepted 1 February 2016

Academic Editor: Chih-Ching Huang

Copyright (C) 2016 Lin Liu et al. This is an open access article distributed under the Creative Commons Attribution License, which permits unrestricted use, distribution, and reproduction in any medium, provided the original work is properly cited.

A ratiometric probe for determining ferric ions $\left(\mathrm{Fe}^{3+}\right)$ was developed based on nitrogen-doped carbon dots (CDs) and rhodamine $\mathrm{B}$ isothiocyanate $(\mathrm{RhB})$, which was then applied to selective detection of $\mathrm{Fe}^{3+}$ in $\mathrm{PB}$ buffer solution, lake water, and tap water. In the sensing system, $\mathrm{FePO}_{4}$ particles deposit on the surface of CDs, resulting in larger particles and surface passivation. The fluorescence (FL) intensity and the light scattering (LS) intensity of CDs can be gradually enhanced with the addition of $\mathrm{Fe}^{3+}$, while the FL intensity of RhB remains constant. The ratiometric light intensity of CDs LS and RhB FL was quantitatively in response to $\mathrm{Fe}^{3+}$ concentrations in a dynamic range of $0.01-1.2 \mu \mathrm{M}$, with a detection limit as low as $6 \mathrm{nM}$. Other metal ions, such as $\mathrm{Fe}^{2+}$, $\mathrm{Al}^{3+}, \mathrm{K}^{+}, \mathrm{Ca}^{2+}$, and $\mathrm{Co}^{2+}$, had no significant interference on the determination of $\mathrm{Fe}^{3+}$. Compared with traditional probes based on single-signal probe for $\mathrm{Fe}^{3+}$ detection, this dual-signal-based ratiometric probe exhibits a more reliable and stable response on target concentration and is characterized by easy operation in a simple fluorescence spectrophotometer.

\section{Introduction}

Quantum dots have been extensively investigated for their applications in chemosensor, biosensor, and bioimaging due to their prominent advantages, such as size-dependent fluorescence emission and wide excitation spectrum, whereas narrow fluorescence emission spectrum and high fluorescence quantum yield resistance to photobleaching. Although traditional quantum dots have been widely used in sensor and imaging, their cytotoxicity is still a controversial question [1-4]. In recent years, carbon dots (CDs) [5-8], with low cytotoxicity $[9,10]$, have attracted extensive research interests due to their good optical properties [5], chemical inertness [11], good biocompatibility [12], and low cost [13]. Due to the above-mentioned advantages, CDs have been widely applied to the development of new methods for detecting ions [1418], organic molecules [19], and proteins [20].

Traditional fluorescent methods mainly depend on the intensity changes of single-signal fluorescence (increased or decreased). Fluorescence signals of these probes were vulnerable to environment (such as temperature, $\mathrm{pH}$, and viscosity), the influence of the sample itself (such as concentration), equipment effects (such as photobleaching and background light), and other factors. Therefore, strict control of the experimental conditions is beneficial to obtain accurate results. Compared with the single-signal fluorescence probe, ratiometric fluorometry provides an intrinsic correction for external interference. In particular, it can eliminate fluctuations of the excitation light intensity by forming the ratio of the intensity of two well-resolved emission peaks. It is independent of the probe concentration and improves the accuracy of the quantification [21-24].

Herein, we fabricated a dual-signal-based ratiometric probe for the detection of $\mathrm{Fe}^{3+}$ and conducted a preliminary test in PB buffer solution. This probe possesses dual emission peaks at $399 \mathrm{~nm}(\mathrm{CDs})$ and $577 \mathrm{~nm}(\mathrm{RhB})$. The addition of $\mathrm{Fe}^{3+}$ to the $\mathrm{CD}-\mathrm{RhB}$ probe resulted in the rapid increase of FL intensity and LS intensity of the CDs, while the FL intensity of RhB remained constant. By taking advantage of the observed ratios in light intensity between CDs LS and 
RhB FL, we fabricated a facile ratiometric probe, which can be used to detect different concentrations of $\mathrm{Fe}^{3+}$ in both $\mathrm{PB}$ buffer solution and actual samples (lake water and tap water).

\section{Experimental}

2.1. Chemicals. Ascorbic acid was obtained from Tianjin Kaitong Chemical Reagents Co., Ltd. (Tianjin, China). Polyoxyethylenebis(amine) (PEG-diamine, MW 2000) was purchased from Aladdin Chemistry Co., Ltd. (Shanghai, China). Rhodamine $\mathrm{B}$ isothiocyanate was obtained from Sigma-Aldrich. $\mathrm{NaCl}, \mathrm{KNO}_{3}, \mathrm{Fe}_{2}\left(\mathrm{SO}_{4}\right)_{3} \cdot 7 \mathrm{H}_{2} \mathrm{O}$, $\mathrm{Zn}\left(\mathrm{NO}_{3}\right)_{2} \cdot 6 \mathrm{H}_{2} \mathrm{O}, \mathrm{CoCl}_{2} \cdot 6 \mathrm{H}_{2} \mathrm{O}, \mathrm{AgNO}_{3}, \mathrm{Al}_{2}\left(\mathrm{SO}_{4}\right)_{3} \cdot 18 \mathrm{H}_{2} \mathrm{O}$, $\mathrm{CaCl}_{2} \cdot 2 \mathrm{H}_{2} \mathrm{O}, \mathrm{CdCl}_{2} \cdot 2.5 \mathrm{H}_{2} \mathrm{O}, \mathrm{CuSO}_{4} \cdot 5 \mathrm{H}_{2} \mathrm{O}$, and $\mathrm{FeSO}_{4} \cdot 7 \mathrm{H}_{2} \mathrm{O}$ were acquired from Shanghai Chemical Reagent Co., Ltd. Dialysis bag (MWCO: 1000) was purchased from Aladdin Chemistry Co., Ltd. All reagents were used without further purification and all the solutions were prepared using ultrapure water obtained from a Millipore water purification system (Milli-Q, Millipore, 18.2 $\mathrm{M} \Omega$ resistivity).

2.2. Apparatus. All fluorescence measurements were carried out with RF-5301PC fluorescence spectrometer (Japan); the sample was placed in a $10 \mathrm{~mm}$ quartz fluorescence cuvette. The UV-Vis absorption spectra were recorded between 200 and $700 \mathrm{~nm}$ on a UV-2450 (JAPAN) with a $1.0 \mathrm{~cm}$ path-length cuvette. High-resolution transmission electron microscopy (HRTEM) (JEM-2100F, JEOL) was used to characterize the size and surface morphology of the as-prepared CDs. Fourier transform infrared spectroscopy (FT-IR) was conducted to detect the chemical identity of CDs on a Nicolet Avatar-330 spectrometer (Thermo Nicolet, USA) with $4 \mathrm{~cm}^{-1}$ resolution using the $\mathrm{KBr}$ pellet technique. All Raman spectra were recorded at room temperature using a Raman spectrometer (Renishaw, UK) equipped with a confocal microscope (Leica, German). Flame atomic absorption spectrometry (FAAS) was obtained with AA240FS spectrometer (Varian, Inc., USA) to detect the content of $\mathrm{Fe}^{3+}$ in the actual samples. All $\mathrm{pH}$ measurements were carried out with a PHS-3C pH Meter (Shanghai, China).

2.3. Synthesis of the CDs. The CDs were synthesized by a hydrothermal method according to the literature with some modifications [25]. $0.10 \mathrm{~g}$ polyethylene glycol diamines and $0.20 \mathrm{~g}$ ascorbic acid were mixed and ground sufficiently in an agate mortar. Then, the mixture was transferred to a $25 \mathrm{~mL}$ hydrothermal reaction kettle and heated for $1 \mathrm{~h}$ at $180^{\circ} \mathrm{C}$ to get a dark brown mixture that was dissolved with $5.0 \mathrm{~mL}$ ultrapure water. Subsequently, the mixture was centrifuged at $12000 \mathrm{rpm}$ for $10 \mathrm{~min}$. The supernatant was collected and then dialyzed against ultrapure water through a dialysis membrane for $24 \mathrm{~h}$ to obtain the pure CDs.

2.4. Preparation of Carbon Nanoprobes. The preparation of carbon nanoprobes followed Huimin Ma's method [26]. The as-prepared CDs solution above was mixed with $\mathrm{RhB}$ at a $4: 1$ mass ratio in $0.10 \mathrm{M} \mathrm{NaHCO}_{3}$ solution at room temperature overnight. Then, the reaction solution was dialyzed in $0.10 \mathrm{M}$ $\mathrm{NaHCO}_{3}$ and ultrapure water every $24 \mathrm{~h}$ by a membrane with a molecular weight cutoff of 1000. After gel chromatographic separation on a Sephadex G-100 column with water as eluent, the product was collected and stored at $4^{\circ} \mathrm{C}$ for further use.

2.5. Characterization by Raman Spectroscopy. The specific experimental procedures were as follows. $10 \mu \mathrm{L}$ of the probe was added into $950 \mu \mathrm{L}$ PB buffer solution (10 mM, pH 7.4) and was mixed to uniformity. Then, $40 \mu \mathrm{L}$ of $30 \mu \mathrm{M} \mathrm{Fe}^{3+}$ was added dropwise into the above solution, and the mixture was centrifuged for $30 \mathrm{~min}$ at $12000 \mathrm{rpm}$. To completely remove the interference of phosphate radical, the supernatant was removed and the precipitate was washed with ultrapure water for three times. Then, ultrapure water was added and the precipitation was dissolved by ultrasound. The obtained liquid dropped on the foil. Raman spectroscopy was recorded at the excitation wavelength of $633 \mathrm{~nm}$ until the liquid was dried.

\section{Results and Discussion}

High-resolution transmission electron microscopy (HRTEM) was used to characterize the surface morphology of the as-prepared CDs. The CDs are well dispersed in aqueous solution and their diameters range from 2.7 to $5.9 \mathrm{~nm}$, with a mean diameter of $4.4 \pm 0.6 \mathrm{~nm}$ (Figures 1 (a) and 1 (b)). The UV-Vis absorption spectrum and the fluorescent spectrum were given in Figure $1(\mathrm{c})$. Due to the $n-\pi^{*}$ transition of CDs, the resultant CDs displayed a broad UV-Vis absorption $[9,25]$. In addition, the UV-Vis absorption spectrum shows a strong peak at $249 \mathrm{~nm}$, which could be ascribed to the $\pi-\pi^{*}$ transition of aromatic $\mathrm{sp}^{2}$ domains $[27,28]$. It can be clearly observed that the most intense peak of CDs appears at $450 \mathrm{~nm}$ (emission wavelength) with excitation at $370 \mathrm{~nm}$. Therefore, CDs show blue color under UV (365 nm) light (Figure 1(c) inset), with the obtained CDs with a quantum yield of $15 \%$. Moreover, the corresponding FL emission spectra of CDs were plotted with the excitation wavelength progressively increasing from 340 to $400 \mathrm{~nm}$ (Figure 1(d)). It is obvious that the FL emission peak of CDs exhibits a large red shift (from $420 \mathrm{~nm}$ to $480 \mathrm{~nm}$ ) with an increase of the excitation wavelength, and the FL intensity increases until $\lambda$ ex $=370 \mathrm{~nm}$, and then decreases slowly. The result that the emission of CDs strongly depends on the excitation wavelength is consistent with the results reported in previous studies [25, 29].

The effects of $\mathrm{pH}$ on emission stability of CDs were monitored in $10 \mathrm{mM}$ PB buffer solution. It is clearly shown in Figure 2 that the FL intensity of CDs nearly has no change at $\mathrm{pH}$ ranging from 3.0 to 10.0 , indicating that $\mathrm{CDs}$ can work in environments at a wide range of $\mathrm{pH}$ values. Fourier transform infrared (FT-IR) spectra were used to identify the functional groups present on the surface of the as-prepared CDs: stretching vibrations of $\mathrm{C}-\mathrm{OH}$ at $3409 \mathrm{~cm}^{-1}$ and C$\mathrm{H}$ at $2901 \mathrm{~cm}^{-1}$; the peak at $1350 \mathrm{~cm}^{-1}$ from the stretching vibration of $\mathrm{C}-\mathrm{NH}$, which indicates the successful adulteration of nitrogen atoms into the CDs; bending vibrations of $\mathrm{N}-\mathrm{H}$ at $1685 \mathrm{~cm}^{-1}$; the vibration absorption band of $\mathrm{C}=\mathrm{O}$ at $1762 \mathrm{~cm}^{-1}$ and the peaks at 1042 and $1105 \mathrm{~cm}^{-1}$ related to the $\mathrm{C}-\mathrm{OH}$ stretching vibrations, which imply the oxygenrich property of the CDs (Figure 3) [5, 25]. These functional 


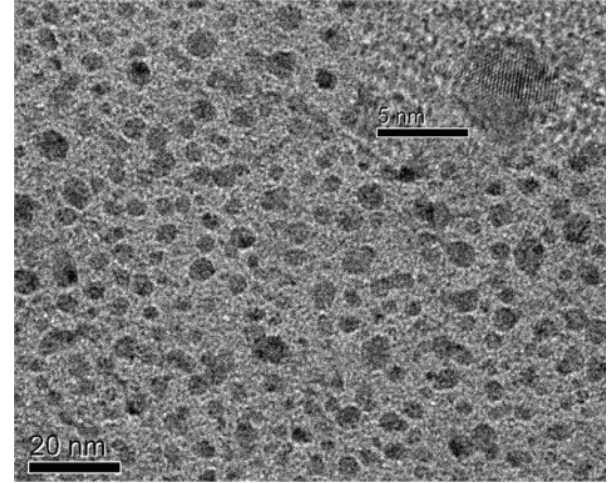

(a)

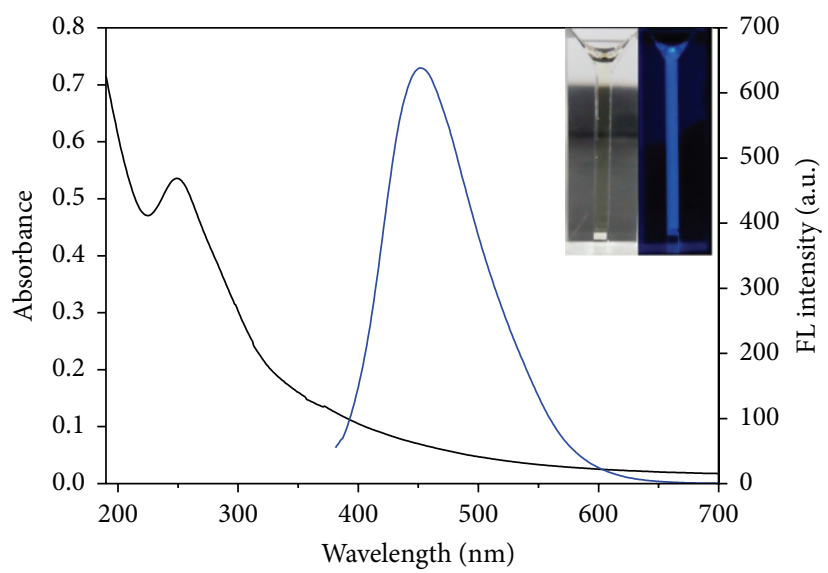

(c)

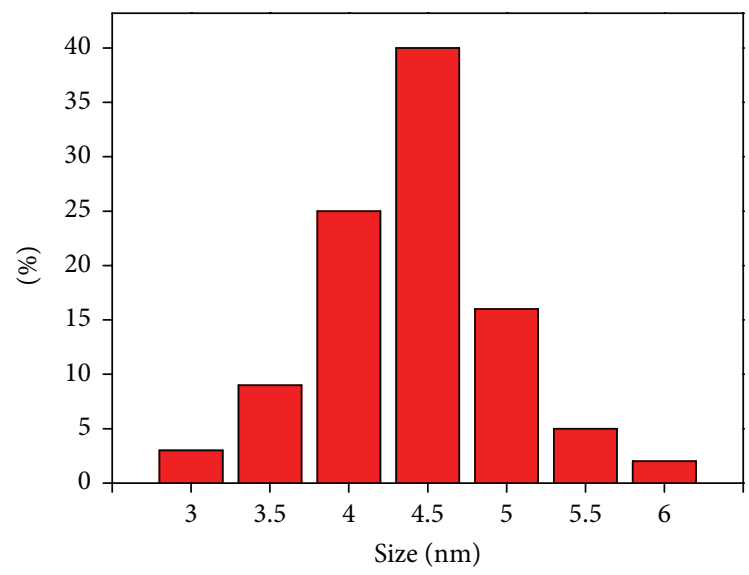

(b)

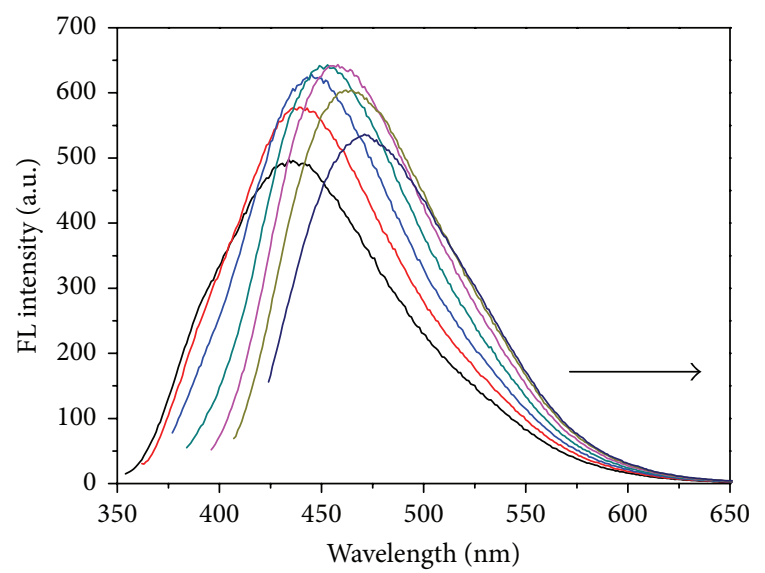

$-340 \mathrm{~nm}$
$-350 \mathrm{~nm}$
$-360 \mathrm{~nm}$
$-370 \mathrm{mn}$

$380 \mathrm{~nm}$

(d)

FIGURE 1: TEM image (a) and size distribution (b) of CDs. (c) UV-Vis absorption spectrum and FL intensity spectrum of CDs (inset shows the photographs of CDs under day light and ultraviolet light). (d) FL emission spectra (with progressively longer excitation wavelengths from 340 to $400 \mathrm{~nm}$ ) of CDs.

groups improve the hydrophilicity and stability of the asprepared CDs, suggesting their great advantage to be used as sensor in aqueous solution.

According to previous reports, doping CDs with trace impurities enables the alteration or an increase in the number of emission centers [30,31]. Nitrogen-doped CDs are the most widely studied doped CDs that exhibit both defectrelated emission and scattering emission. Figure S1 in Supplementary Material available online at http://dx.doi.org/10.1155/ 2016/4939582 indicates that the LS peak of CDs at $399 \mathrm{~nm}$ was observed after quench of FL. The defect-related emission leads to FL in a wavelength range of $400-700 \mathrm{~nm}$. Whilst, nitrogen-doped CDs are capable of scattering the incident light and the LS intensity can be greatly increased upon particle aggregation [32]. This probe possesses distinguished advantages over other probes for the LS resulting from target-induced aggregation of nanoparticles $[33,34]$. $\mathrm{RhB}$ was selected as the reference signal in the probe due to its chemical inertness in the presence of $\mathrm{Fe}^{3+}$. As shown in Figure S2, the hydrodynamic size distribution of CD-RhB probe was increased after the addition of $\mathrm{Fe}^{3+}$. Figure 4(a) presents the emission spectra of $\mathrm{RhB}$ upon the addition of $\mathrm{Fe}^{3+}$. It is clear that the FL spectra remain almost unchanged with the addition of $\mathrm{Fe}^{3+}$; in contrast, when the concentration of $\mathrm{Fe}^{3+}$ ranges from 0.01 to $1.2 \mu \mathrm{M}$, the light intensity of CDs increases in the presence of $\mathrm{Fe}^{3+}$, especially the intensity of LS. Based on these findings, we expect that the probe can selectively detect $\mathrm{Fe}^{3+}$ with high sensitivity. As shown in Figure 4(a), the LS intensity of CDs shows a rising trend and the FL intensity of $\mathrm{RhB}$ basically remains unchanged in the presence of different concentrations of $\mathrm{Fe}^{3+}$. The ratios in light intensity between CD LS and RhB FL $\left(I_{399} / I_{577}\right)$ display a good linear relationship with the $\mathrm{Fe}^{3+}$ concentrations ranging from 0.01 


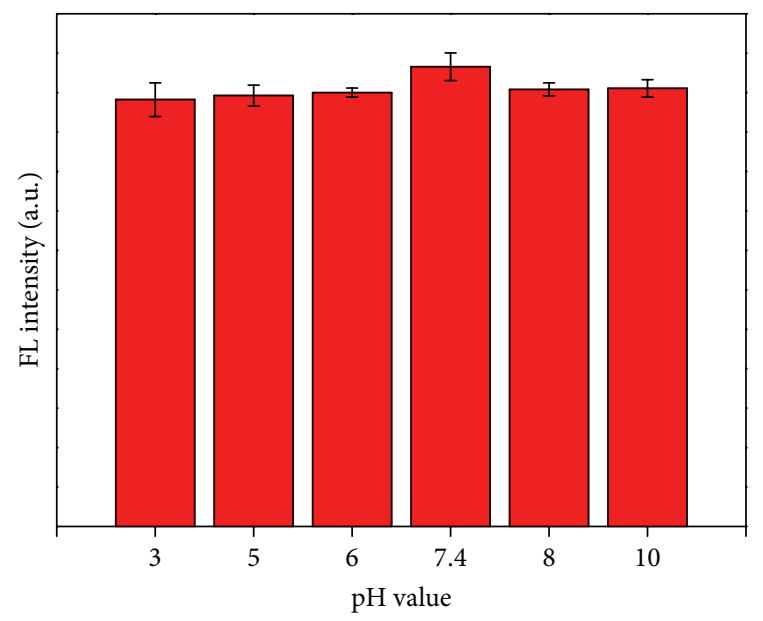

FIGURE 2: FL intensity of CDs in aqueous solutions with different $\mathrm{pH}$ values. All values were obtained based on three independent measurements.

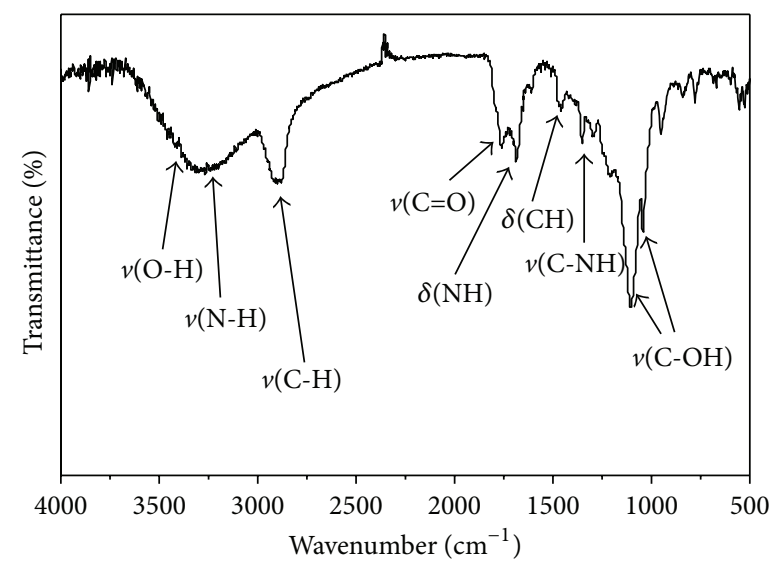

FIgURE 3: FT-IR spectra of the CDs.

to $1.2 \mu \mathrm{M}$ with a detection limit of $6 \mathrm{nM}$ under the optimum experimental conditions (Figure 4(b)). The linear equation is $I_{399} / I_{577}=0.256+0.379 c(c: \mu \mathrm{M})$ and the correlation coefficient $R^{2}$ is 0.996 , where $I_{399}$ and $I_{577}$ are the light intensities at $399 \mathrm{~nm}$ and $577 \mathrm{~nm}$ in the absence or the presence of $\mathrm{Fe}^{3+}$, respectively.

The specificity of the CD-RhB probe for $\mathrm{Fe}^{3+}$ with a variety of metal ions including $\mathrm{Fe}^{2+}, \mathrm{K}^{+}, \mathrm{Co}^{2+}, \mathrm{Zn}^{2+}, \mathrm{Al}^{3+}$, $\mathrm{Cu}^{2+}, \mathrm{Ag}^{+}, \mathrm{Na}^{+}, \mathrm{Ca}^{2+}$, and $\mathrm{Cd}^{2+}$ was evaluated in PB buffer solution (10 mM, pH 7.4). The $I_{399} / I_{577}$ ratios of different metal ions at the same concentration $(1.0 \mu \mathrm{M})$ were evaluated in $\mathrm{PB}$ buffer solution. As shown in Figure 5, there is no significant interference on the probe from the above cations. This result indicates that our CD-RhB probe exhibits a high specificity for $\mathrm{Fe}^{3+}$ over other metal ions.

\section{Possible Mechanism by Which $\mathrm{Fe}^{3+}$ Affects Probe Light Intensity}

We constructed CD-RhB probe through the conjugation of $\mathrm{CDs}$ and $\mathrm{RhB}$ molecules. With the addition of $\mathrm{Fe}^{3+}$, the FL

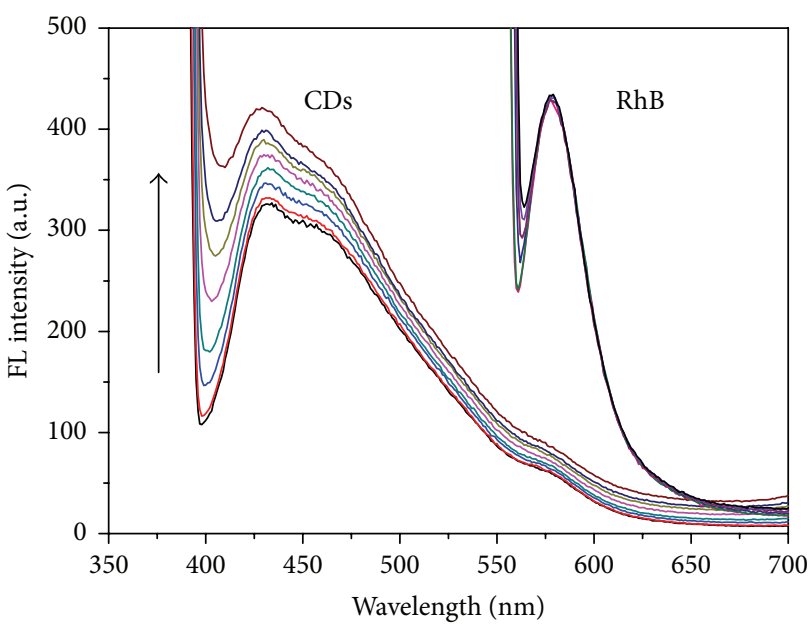

(a)

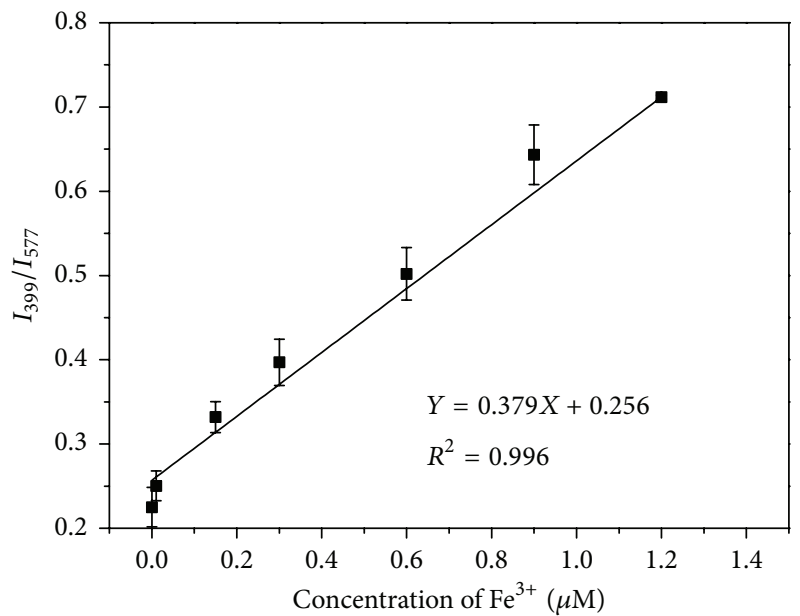

(b)

FIgURE 4: (a) FL emission spectra of the $\mathrm{CD}-\mathrm{RhB}$ probe with different concentrations of $\mathrm{Fe}^{3+}$ (from bottom to top, 0, 0.01, 0.15, $0.3,0.6,0.9$, and $1.2 \mu \mathrm{M})$ in PB buffer solution (10 mM, pH 7.4). (b) The $I_{399} / I_{577}$ ratios of the probe versus the concentration of $\mathrm{Fe}^{3+}$ within the range of $0.01-1.2 \mu \mathrm{M}$. The error bars represent standard deviations based on three independent measurements.

and LS of CDs in the probe were gradually enhanced, while the FL of the RhB remained constant. Therefore, we propose a working mechanism of the $\mathrm{FePO}_{4}$-mediated LS and FL increase of CDs: while $\mathrm{FePO}_{4}$ particles are deposited on the surface, the defects of the CDs are filled, and thus the LS intensity can be greatly increased along with the appearance of larger particles. In addition, the interactions of $\mathrm{FePO}_{4}$ particles with CDs result in surface passivation of the CDs, thereby enhancing the FL intensity (Scheme 1). Then, the hypothesis was verified by Raman spectroscopy. As shown in Figure 6, a very prominent peak appears at $1003 \mathrm{~cm}^{-1}$, which indicates the presence of $\mathrm{FePO}_{4}$ according to the previous study [35]. Except for the peak of $\mathrm{FePO}_{4}$, no responses were observed for CDs, $\mathrm{RhB}$, or CD-RhB nanohybrid on the whole Raman spectrum. 

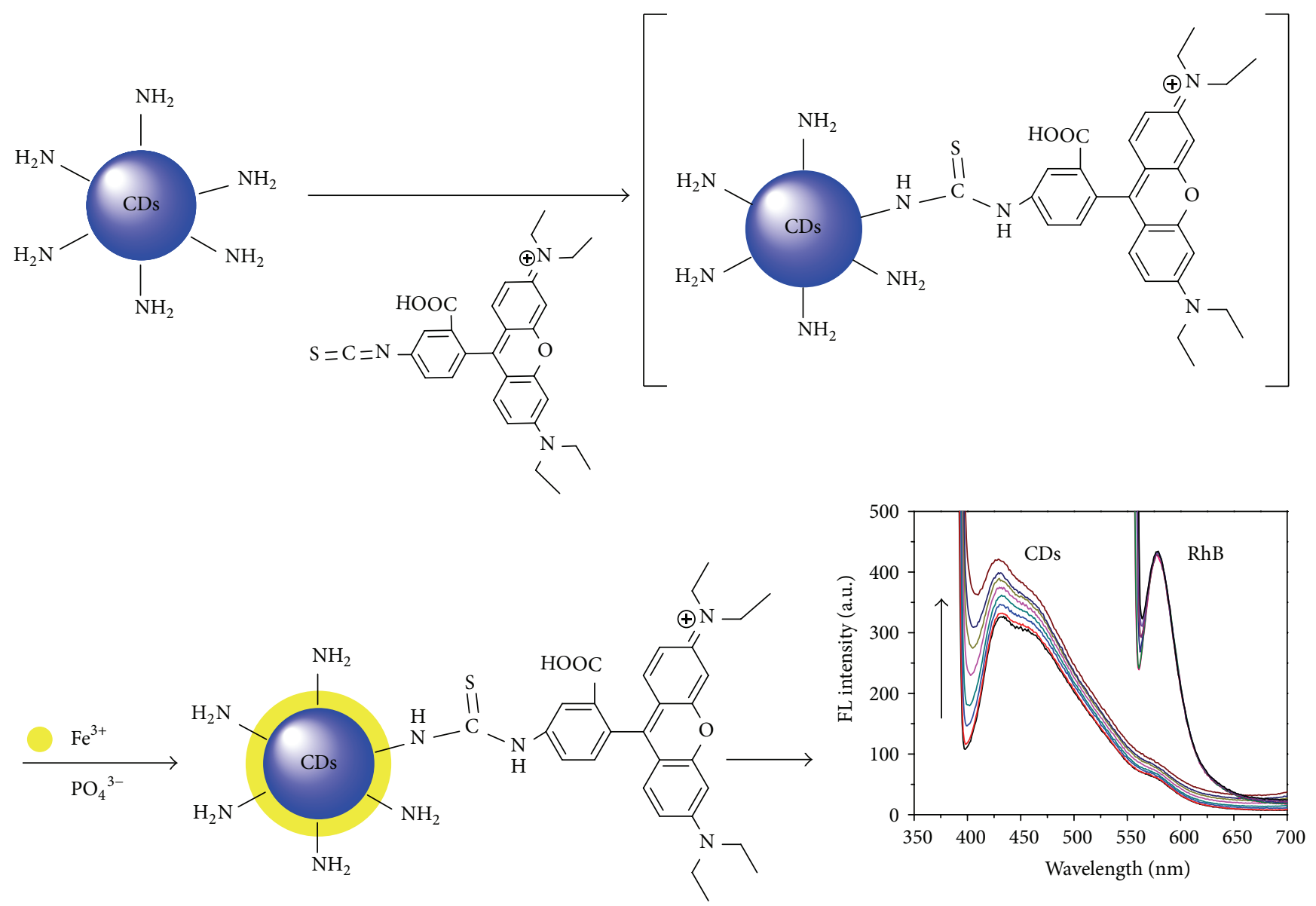

SCHEME 1: Dual-signal ratiometric probe of $\mathrm{Fe}^{3+}$ based on a CD-RhB nanohybrid system.

TABLE 1: Determination of $\mathrm{Fe}^{3+}$ in lake water and tap water with the proposed method.

\begin{tabular}{lcc}
\hline Sample & Proposed method $(\mu \mathrm{M})$ & FAAS $(\mu \mathrm{M})$ \\
\hline Sample 1 (lake water) & $0.036 \pm 0.006$ & 0.044 \\
Sample 2 (tap water) & $0.060 \pm 0.009$ & 0.065 \\
\hline
\end{tabular}

\section{Calibration and Application in Actual Samples}

To demonstrate the practicability of the ratiometric probe, its detection performance was evaluated in actual water samples. The proposed method was successfully applied to determine $\mathrm{Fe}^{3+}$ content in lake water (sample 1) and tap water (sample 2). The lake water was taken from South Lake (Wuhan), and the tap water was collected from our laboratory. After the environmental water samples were centrifuged at $6000 \mathrm{rpm}$ for $30 \mathrm{~min}$ and then filtered through $0.22 \mu \mathrm{m}$ filter membranes, they were used for $\mathrm{Fe}^{3+}$ analysis. Parallel measurements were carried out with three similar water samples by FAAS. The results obtained by the proposed method are in good consistency with those of FAAS (given in Table 1). To further validate the determination, addition and recovery of $\mathrm{Fe}^{3+}$ in actual water samples were also studied,

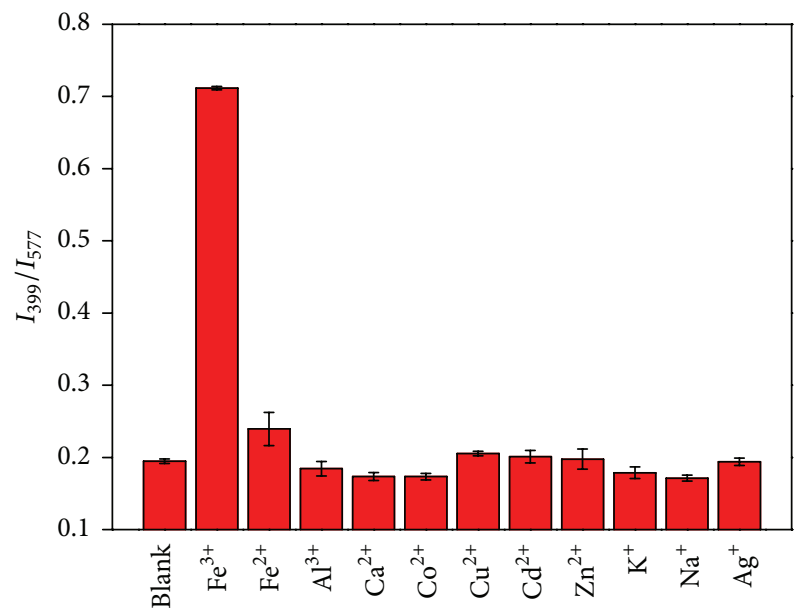

FIGURE 5: Selectivity of the CD-RhB probe toward $\mathrm{Fe}^{3+}$ over other ions. The concentration of metal ions is $1.0 \mu \mathrm{M}$. The error bars represent standard deviations based on three independent measurements.

and the obtained recoveries ranged from $97.2 \%$ to $108.8 \%$ (Table S1 in the Supporting Information). 


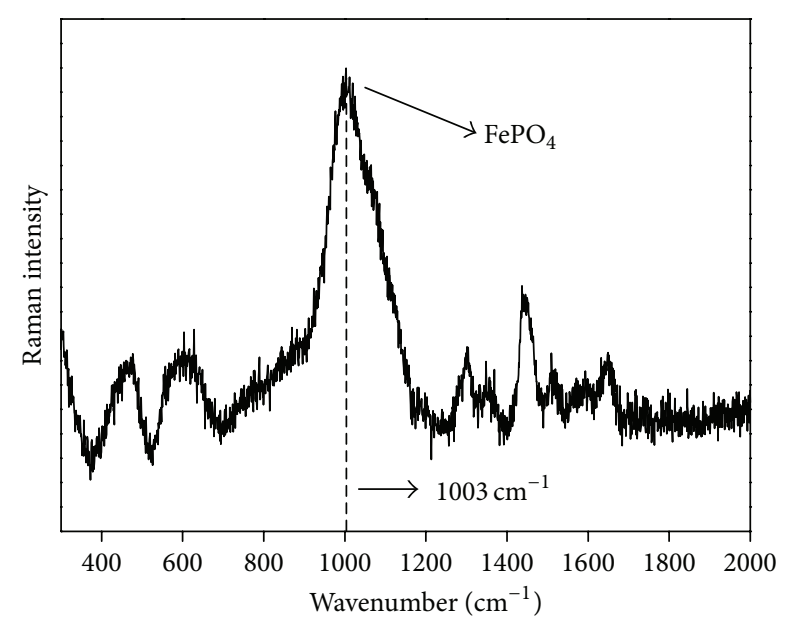

Figure 6: Raman spectra of $\mathrm{FePO}_{4}$ collected as a function of power. The wavelength of the excitation laser is $633 \mathrm{~nm}$.

\section{Conclusion}

In summary, the as-prepared nitrogen-doped CDs are stable, bright, and with good water solubility. We have demonstrated that $\mathrm{CDs}$ and $\mathrm{RhB}$ form a nanohybrid probe through their chemical reaction. This $\mathrm{CD}-\mathrm{RhB}$ probe was successfully used as a ratiometric probe to detect $\mathrm{Fe}^{3+}$ in lake water and tap water, showing the good selectivity and sensitivity. The detection limit is as low as $6 \mathrm{nM}$. Compared with the previously reported sensing methods, this $\mathrm{CD}-\mathrm{RhB}$ probe displays several important advantages. First, this strategy avoids the use of traditional semiconductor quantum dots and organic solvents; thus, it is more environmental friendly. Second, the ratiometric probe can effectively eliminate the background interference and the fluctuation of detection conditions by depending on two kinds of signals: CDs LS and RhB FL, and thus it is more reliable than single-signal detection strategy. Third, this ratiometric probe for $\mathrm{Fe}^{3+}$ determination exhibits more sensitive signals than quenching probe. It is expected that this strategy may offer a new approach for developing green, low-cost, and sensitive dual-signal probes for practical applications.

\section{Conflict of Interests}

The authors declare that there is no conflict of interests regarding the publication of this paper.

\section{Acknowledgments}

The authors gratefully acknowledge financial support from the National Natural Science Foundation of China (21305049, 21205043, and 31372439). They also thank Professor Zuoxiong Liu for editing the English language.

\section{References}

[1] K. Zhang, H. Zhou, Q. Mei et al., "Instant visual detection of trinitrotoluene particulates on various surfaces by ratiometric fluorescence of dual-emission quantum dots hybrid," Journal of the American Chemical Society, vol. 133, no. 22, pp. 8424-8427, 2011.

[2] D. W. Huang, C. G. Niu, X. Y. Wang, X. X. Lv, and G. M. Zeng, “'Turn-on' fluorescent sensor for $\mathrm{Hg}^{2+}$ based on singlestranded DNA functionalized Mn:CdS/ZnS quantum dots and gold nanoparticles by time-gated mode," Analytical Chemistry, vol. 85, no. 2, pp. 1164-1170, 2013.

[3] J. G. Liang, S. Huang, D. Y. Zeng et al., "CdSe quantum dots as luminescent probes for spironolactone determination," Talanta, vol. 69, no. 1, pp. 126-130, 2006.

[4] H. M. Wu, J. G. Liang, and H. Y. Han, "A novel method for the determination of $\mathrm{Pb} 21$ based on the quenching of the fluorescence of CdTe quantum dots," Microchim Acta, vol. 161, no. 1, pp. 81-86, 2008.

[5] S. J. Zhu, Q. N. Meng, L. H. Wang et al., "Highly photoluminescent carbon dots for multicolor patterning, sensors, and bioimaging," Angewandte Chemie-International Edition, vol. 52, no. 14, pp. 3953-3957, 2013.

[6] M. J. Krysmann, A. Kelarakis, P. Dallas, and E. P. Giannelis, "Formation mechanism of carbogenic nanoparticles with dual photoluminescence emission," Journal of the American Chemical Society, vol. 134, no. 2, pp. 747-750, 2012.

[7] D. Y. Pan, J. C. Zhang, Z. Li, C. Wu, X. M. Yan, and M. H. Wu, "Observation of $\mathrm{pH}$-, solvent-, spin-, and excitation-dependent blue photoluminescence from carbon nanoparticles," Chemical Communications, vol. 46, no. 21, pp. 3681-3683, 2010.

[8] Y. L. Zhai, Z. J. Zhu, C. Z. Zhu, J. T. Ren, E. Wang, and S. J. Dong, "Multifunctional water-soluble luminescent carbon dots for imaging and $\mathrm{Hg}^{2+}$ sensing," Journal of Materials Chemistry $B$, vol. 2, no. 40, pp. 6995-6999, 2014.

[9] M. Zheng, Z. G. Xie, D. Qu et al., "On-off-on fluorescent carbon dot nanosensor for recognition of chromium(VI) and ascorbic acid based on the inner filter effect," ACS Applied Materials and Interfaces, vol. 5, no. 24, pp. 13242-13247, 2013.

[10] W. J. Lu, X. J. Gong, Z. H. Yang et al., "High-quality watersoluble luminescent carbon dots for multicolor patterning, sensors, and bioimaging," RSC Advances, vol. 5, no. 22, pp. 16972-16979, 2015.

[11] S. N. Qu, X. Y. Wang, Q. P. Lu, X. Y. Liu, and L. J. Wang, "A biocompatible fluorescent ink based on water-soluble luminescent carbon nanodots," Angewandte Chemie-International Edition, vol. 51, no. 49, pp. 12215-12218, 2012.

[12] L. Wang and H. S. Zhou, "Green synthesis of luminescent nitrogen-doped carbon dots from milk and its imaging application," Analytical Chemistry, vol. 86, no. 18, pp. 8902-8905, 2014.

[13] J. J.Zhou, Z. H. Sheng, H. Y. Han, M. Q. Zou, and C. X. Li, "Facile synthesis of fluorescent carbon dots using watermelon peel as a carbon source," Materials Letters, vol. 66, no. 1, pp. 222-224, 2012.

[14] P. Miao, Y. G. Tang, K. Han, and B. D. Wang, "Facile synthesis of carbon nanodots from ethanol and their application in ferric(III) ion assay," Journal of Materials Chemistry A, vol. 3, no. 29, pp. 15068-15073, 2015.

[15] S. W. Zhang, J. X. Li, M. Y. Zeng, J. Z. Xu, X. K. Wang, and W. P. $\mathrm{Hu}$, "Polymer nanodots of graphitic carbon nitride as effective fluorescent probes for the detection of $\mathrm{Fe}^{3+}$ and $\mathrm{Cu}^{2+}$ ions," Nanoscale, vol. 6, no. 8, pp. 4157-4162, 2014.

[16] K. G. Qu, J. S. Wang, J. S. Ren, and X. G. Qu, "Carbon dots prepared by hydrothermal treatment of dopamine as an effective fluorescent sensing platform for the label-free detection of 
iron(III) ions and dopamine," Chemistry - A European Journal, vol. 19, no. 22, pp. 7243-7249, 2013.

[17] Y. P. Sun, C. Shen, J. Wang, and Y. Lu, "Facile synthesis of biocompatible N, S-doped carbon dots for cell imaging and ion detecting," RSC Advances, vol. 5, no. 21, pp. 16368-16375, 2015.

[18] Y. M. Guo, L. F. Zhang, S. S. Zhang, Y. Yang, X. H. Chen, and M. C. Zhang, "Fluorescent carbon nanoparticles for the fluorescent detection of metal ions," Biosensors and Bioelectronics, vol. 63, pp. 61-71, 2015.

[19] X. M. Yang, Y. W. Luo, S. S. Zhu, Y. J. Feng, Y. Zhuo, and Y. Dou, "One-pot synthesis of high fluorescent carbon nanoparticles and their applications as probes for detection of tetracyclines," Biosensors and Bioelectronics, vol. 56, pp. 6-11, 2014.

[20] J. J. Gu, D. H. Hu, W. N. Wang et al., "Carbon dot cluster as an efficient 'off-on' fluorescent probe to detect $\mathrm{Au}(\mathrm{III})$ and glutathione," Biosensors and Bioelectronics, vol. 68, pp. 27-33, 2015.

[21] Q. Mu, Y. Li, H. Xu, Y. F. Ma, W. H. Zhu, and X. H. Zhong, "Quantum dots-based ratiometric fluorescence probe for mercuric ions in biological fluids," Talanta, vol. 119, pp. 564$571,2014$.

[22] Y.-Q. Wang, T. Zhao, X.-W. He, W.-Y. Li, and Y.-K. Zhang, "A novel core-satellite CdTe/Silica/Au NCs hybrid sphere as dualemission ratiometric fluorescent probe for $\mathrm{Cu}^{2+}$," Biosensors and Bioelectronics, vol. 51, pp. 40-46, 2014.

[23] M. H. Lan, J. F. Zhang, Y.-S. Chui et al., "Carbon nanoparticlebased ratiometric fluorescent sensor for detecting mercury ions in aqueous media and living cells," ACS Applied Materials and Interfaces, vol. 6, no. 23, pp. 21270-21278, 2014.

[24] X. Gao, C. Ding, A. Zhu, and Y. Tian, "Carbon-dot-based ratiometric fluorescent probe for imaging and biosensing of superoxide anion in live cells," Analytical Chemistry, vol. 86, no. 14, pp. 7071-7078, 2014.

[25] H. J. Zhang, Y. L. Chen, M. J. Liang et al., "Solid-phase synthesis of highly fluorescent nitrogen-doped carbon dots for sensitive and selective probing ferric ions in living cells," Analytical Chemistry, vol. 86, no. 19, pp. 9846-9852, 2014.

[26] W. Shi, X. H. Li, and H. M. Ma, "A tunable ratiometric $\mathrm{pH}$ sensor based on carbon nanodots for the quantitative measurement of the intracellular $\mathrm{pH}$ of whole cells," Angewandte ChemieInternational Edition, vol. 51, pp. 6432-6435, 2012.

[27] G. Eda, Y.-Y. Lin, C. Mattevi et al., "Blue photoluminescence from chemically derived graphene oxide," Advanced Materials, vol. 22, no. 4, pp. 505-509, 2010.

[28] D. Wang, L. Wang, X. Dong, Z. Shi, and J. Jin, "Chemically tailoring graphene oxides into fluorescent nanosheets for $\mathrm{Fe}^{3+}$ ion detection," Carbon, vol. 50, no. 6, pp. 2147-2154, 2012.

[29] S. Liu, J. Tian, L. Wang, Y. Luo, J. Zhai, and X. Sun, "Preparation of photoluminescent carbon nitride dots from $\mathrm{CCl}_{4}$ and 1,2ethylenediamine: a heat-treatment-based strategy," Journal of Materials Chemistry, vol. 21, no. 32, pp. 11726-11729, 2011.

[30] S. C. Erwin, L. J. Zu, M. I. Haftel, A. L. Efros, T. A. Kennedy, and D. J. Norris, "Doping semiconductor nanocrystals," Nature, vol. 436, no. 7047, pp. 91-94, 2005.

[31] D. J. Norris, A. L. Efros, and S. C. Erwin, "Doped nanocrystals," Science, vol. 319, no. 5871, pp. 1776-1779, 2008.

[32] X. D. Chen, Y. P. Dong, L. Fan, D. C. Yang, and M. Q. Zhang, "Resonance scattering method for the ultrasensitive determination of peptides using semiconductor nanocrystals," Analytica Chimica Acta, vol. 597, no. 2, pp. 300-305, 2007.
[33] H. Jans, X. Liu, L. Austin, G. Maes, and Q. Huo, "Dynamic light scattering as a powerful tool for gold nanoparticle bioconjugation and biomolecular binding studies," Analytical Chemistry, vol. 81, no. 22, pp. 9425-9432, 2009.

[34] P. Wu, L.-N. Miao, H.-F. Wang, X.-G. Shao, and X.-P. Yan, "A multidimensional sensing device for the discrimination of proteins based on manganese-doped ZnS quantum dots," Angewandte Chemie-International Edition, vol. 50, no. 35, pp. 8118-8121, 2011.

[35] C. M. Burba, J. M. Palmer, and B. S. Holinsworth, "Laserinduced phase changes in olivine $\mathrm{FePO}_{4}$ : a warning on characterizing $\mathrm{LiFePO}_{4}$-based cathodes with Raman spectroscopy," Journal of Raman Spectroscopy, vol. 40, no. 2, pp. 225-228, 2009. 

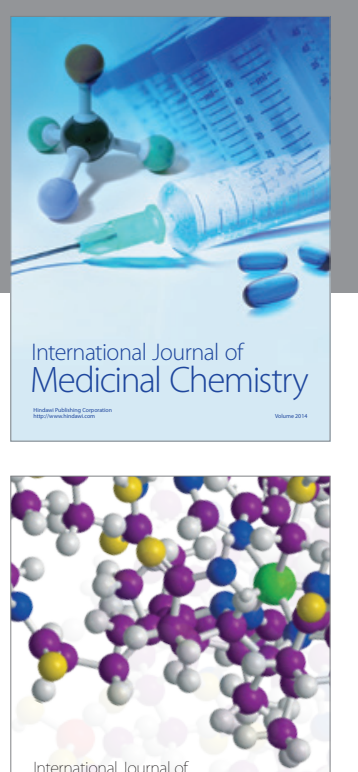

Carbohydrate Chemistry

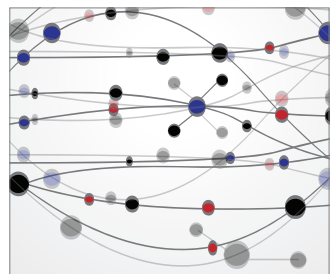

The Scientific World Journal
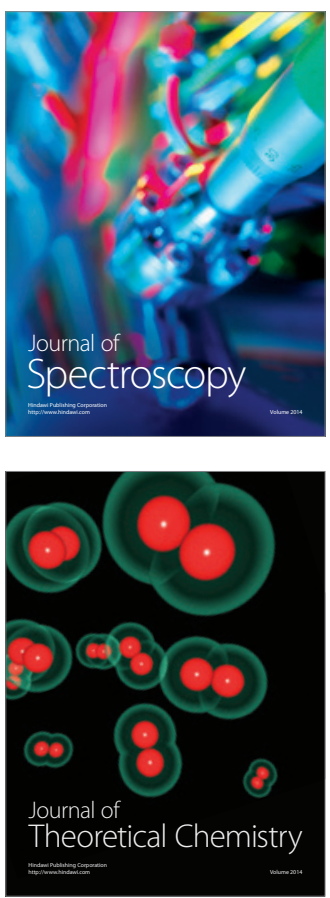
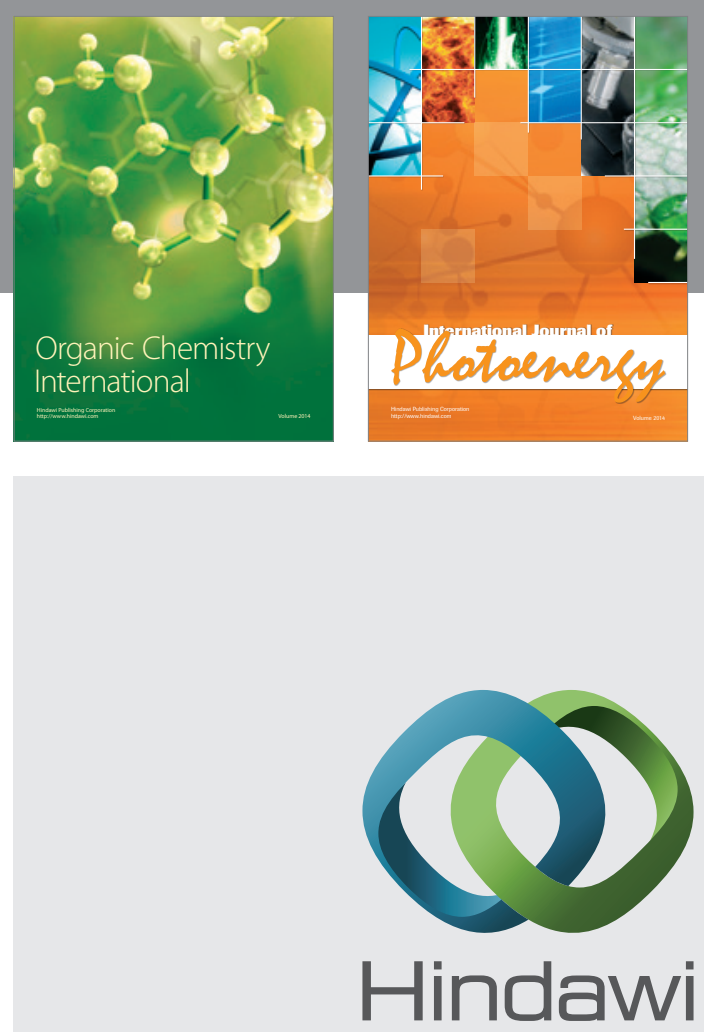

Submit your manuscripts at

http://www.hindawi.com

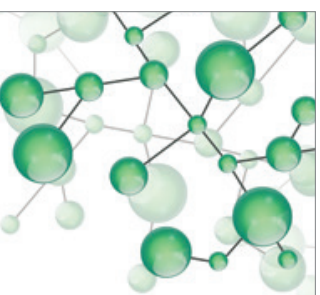

International Journal of

Inorganic Chemistry

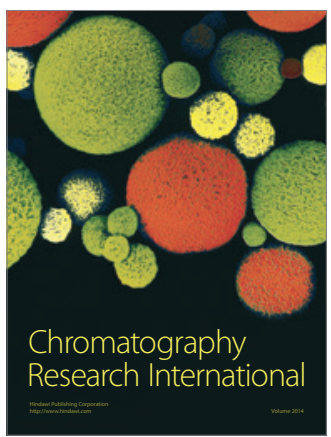

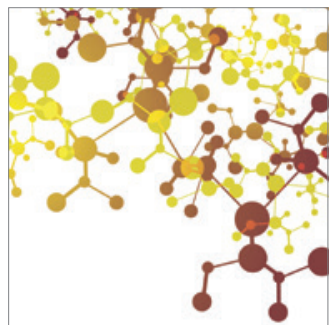

Applied Chemistry
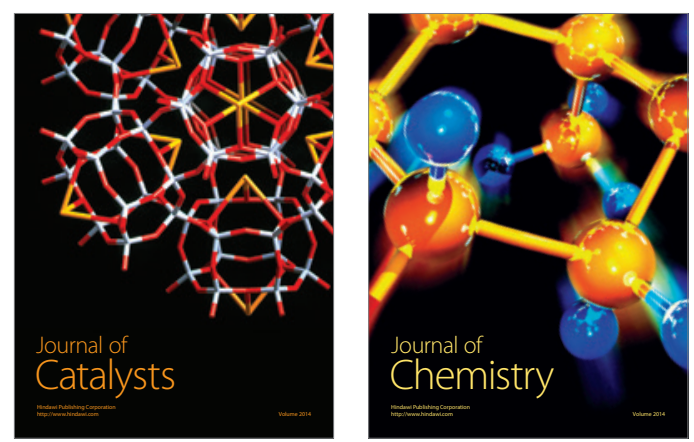
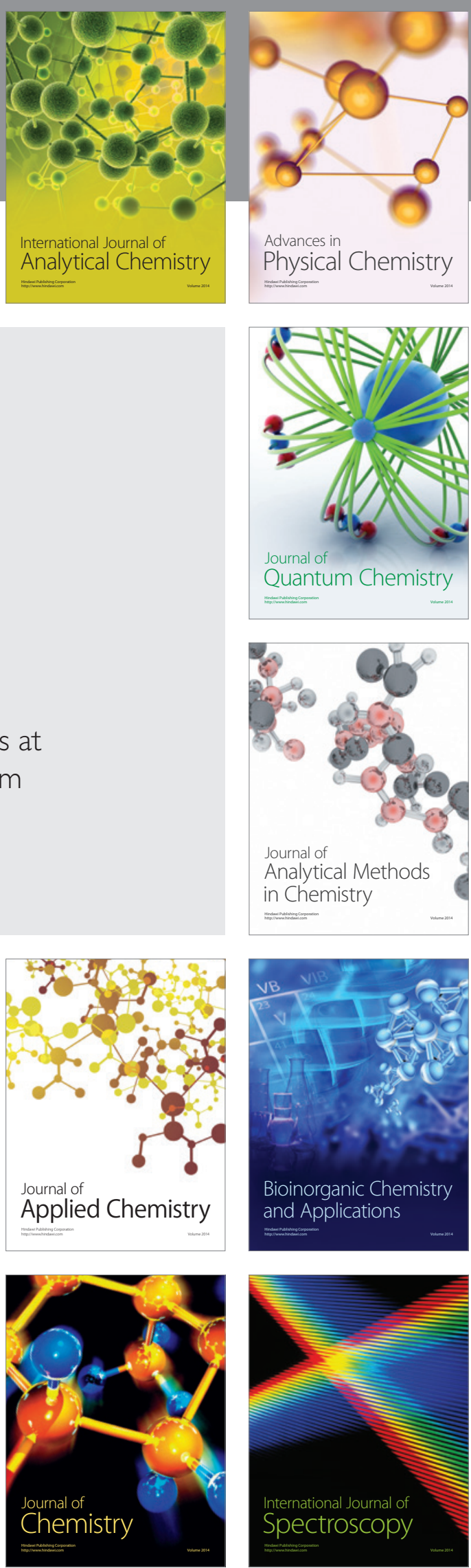